Research Article

\title{
Determinants of Emergency Contraceptive Pill use among the Patients Presenting for Pregnancy Termination at Tertiary Care Hospital in Western Maharashtra
}

\author{
PS Wakankar', MA Parande
}

${ }^{1}$ Intern, ${ }^{2}$ Associate Professor, Department of Preventive and Social Medicine, BJ Govt. Medical College, Pune, Maharashtra, India. DOI: https://doi.org/10.24321/2454.325X.201917

\section{I $\quad \mathbf{N} \quad \mathbf{F} \quad \mathbf{O}$}

\section{Corresponding Author:}

MA Parande, Department of Preventive and Social Medicine, BJ Govt. Medical College, Pune, Maharashtra, India.

E-mail Id:

drparandemalan@rediffmail.com

Orcid Id:

https://orcid.org/0000-0003-2581-6164

How to cite this article:

Wakankar PS, Parande MA. Determinants of Emergency Contraceptive Pill use among the Patients Presenting for Pregnancy Termination at Tertiary Care Hospital in Western Maharashtra. Int J Preven Curat Comm Med 2019; 5(3): 24-30.

Date of Submission: 2019-09-21

Date of Acceptance: 2019-11-16

\section{$\begin{array}{llllllll}\mathbf{A} & \mathbf{B} & \mathbf{S} & \mathbf{T} & \mathbf{R} & \mathbf{A} & \mathbf{C} & \mathbf{T}\end{array}$}

Background: Emergency Contraceptives (EC) are used to prevent unplanned pregnancies thereby preventing the occurrence and consequences of unplanned pregnancy. Emergency contraception is widely available in India. Yet the use of EC is very low and abortion rate in cities is high.

Objective: To assess the practice and determinants of use of emergency contraceptive pills among women presenting for pregnancy termination in a tertiary care hospital.

Material and Methods: This was a Cross-sectional, hospital-based study, conducted among the women of reproductive age group presenting for termination of pregnancy in a tertiary care hospital in Western Maharashtra. The study was conducted for a period of three months from May to July, 2016. Data was collected with the help of a preformed and prestructured questionnaire. A total of 150 cases were enrolled in the study. The data was tabulated and analyzed using Epi Info and MS Excel.

Result: The knowledge of emergency contraception was seen in $34.0 \%$ subjects, out of which only $7.3 \%$ had good knowledge. Attitude wise assessment of emergency contraception showed that $74.7 \%$ subjects had favourable attitude towards its use while only $21 \%$ participants used emergency contraceptive pills. The study revealed that there is a low trend of use of modern contraceptives. The major reason for low usage was lack of adequate knowledge on the method, misperceptions of the adverse effects of this method, fear of effect on future fertility. Factors like women belonging to urban area, education, socioeconomic status and knowledge of contraception and emergency contraception and ever used contraceptive were the significant determinants of EC use.

Conclusion: It is concluded that knowledge and use of emergency contraceptive is low while all had favourable attitude towards its use. Awareness is to be created among the community through information, education and communication so that the its use will be increased.

Keywords: Knowledge, Emergency Contraception, Abortion Seekers 


\section{Introduction}

Pregnancy is an important event in the life of a woman. Unfortunately, all pregnancies are not welcomed. Each year worldwide, 85 million out of 208 million pregnancies (41\%) are unintended. ${ }^{1}$ Reasons for unplanned pregnancies are either woman's failure to use a contraceptive method or failure to use a method correctly. ${ }^{2}$

Over the past 40 years, there have been significant advances in contraceptive methods; its approaches and services. However, contraceptive practices are no longer in wide use. $^{3}$ The problem of underutilization of contraception is complicated by deep-rooted religious and other beliefs and attitude and prevailing practices in families. Ideally, a child should be born because it is wanted, not because it cannot be prevented and this can be made possible by the constructive use of contraceptive methods. ${ }^{4}$ The old idea of prevention of conception is replace by control of conception. It was observed from the data of year 20102014 that there were around 25 million unsafe abortions per year; out of which one third were performed under least safe or unsafe conditions by untrained persons using dangerous methods. These unsafe abortions will lead to an estimated 7 million complications. The mortality rate is 30 per 100000 unsafe abortions in developed region and it increases to 220 per 100000 unsafe abortions in developing region. ${ }^{5}$

The present youngsters enjoy more freedom of movement than it was a decade ago. ${ }^{6}$ Given increasing adolescent sexual activity and decreasing age of first sex in developing countries, the use of contraceptives to prevent unwanted pregnancies and unsafe abortion is especially important. Unwanted pregnancy is a social as well as economic burden for the society with a high complication rate. ${ }^{7}$ A safe, effective and handy method to prevent unplanned pregnancy is available in the form of Emergency Contraception (EC). $\mathrm{EC}$, otherwise known as postcoital contraception, refers to a group of birth control modalities that, when used after unprotected intercourse within defined time constrains (within 72 hours), can markedly reduce the risk of a resultant unintended pregnancy. ${ }^{8}$ In India, EC pills can be found in any drug retails in a two dose oral pills that should be taken in 12 hours apart. According to the information on the leaflet distributed with the drug, the two doses should be taken within 72 hours after exposure to unprotected sex. In major cities even though EC is easily accessible from drug stores, abortion rate is quite high. By timely and judicious use of EC, $75 \%-85 \%$ of the unplanned pregnancies, and thereby unsafe abortions, can be prevented. ${ }^{9}$ This study assessed the practice and determinants of use of emergency contraceptive pills among women presenting for pregnancy termination in a tertiary care hospital in Western Maharashtra. The outcome of this study will be used to put interventions in place in order to increase the use of EC thereby reverse the occurrence of unwanted pregnancy and its sequelae.

\section{Objectives}

- To study the practice of emergency contraceptive pills among women presenting for pregnancy termination in a tertiary care hospital.

- To assess determinants of use of emergency contraceptive pills among them.

\section{Materials and Methods}

This was a Cross-sectional, hospital-based study, conducted among the women of reproductive age group presenting for termination of pregnancy in a tertiary care hospital in Western Maharashtra. The study was conducted for a period of three months from May to July, 2016. Sample size was calculated assuming the proportion of EC use as $9.7 \%{ }^{10}$ among the women attending the MTP centre of a tertiary care hospital with $5 \%$ margin of error (Absolute error) and $95 \%$ confidence level, it came to be 135 which is rounded off to 150 . Daily number of women requesting pregnancy termination were $2-3$, so per month around 50 were requesting pregnancy termination and during three months period 150 patients were covered.

\section{Inclusion Criteria}

All women who were requesting induced abortion and consented to be interviewed during the above mentioned three month's period.

\section{Exclusion Criteria}

Women who were requesting MTP in cases of fetal abnormality or who were severely ill and not willing to participate.

Data was collected with a preformed and prestructured questionnaire which included age, religion, income, marital status, parity, h/o previous MTPs, indications for MTP, knowledge of contraception and EC, attitude towards EC and ever use of EC. The interview was taken by the investigator explaining the questionnaire in local language. A total of 150 cases were enrolled in the study. Permission of Institute Ethical Committee was taken. A written informed consent was obtained from all participants. Study participants, whose age was less than 18 years, assent was taken from the study participants. For this study group, as the issue is very sensitive, consent was not obtained from the care taker/ guardian.

The data was tabulated and analyzed using Epi Info and MS Excel. Descriptive statistics (percentages, mean, Standard deviation), Odd's ratio, Chi-square tests were done and significance of tests were decided at $p$-value 0.05 . Tables and graphs have been used to depict results. 


\section{Operational Definitions"}

\section{Knowledge}

Awareness about the types, time limit to be taken after unprotected sex, effectiveness after a menstrual delay and content of emergency contraceptives.

\section{Assessment of Knowledge Score}

Four knowledge-based questions were taken into consideration. A score of 1 was assigned for right answer and 0 for wrong answer.

\section{Interpretation of Total Score}

3-4 = Good knowledge; $1-2=$ Fair knowledge and $0=$ No knowledge

\section{Attitude}

The way to which clients are thinking or behaving towards emergency contraceptive.

\section{Assessment of Attitude}

Four relevant questions were considered. Each positive answer was awarded 1 mark.

\section{Interpretation of Score}

3-4 = Favourable attitude and 0-2 = Not favourable attitude

\section{Practice}

Trend of use of emergency contraceptives among women who seek abortion care.

\section{Result}

Total participants enrolled in this study were 150 . The sociodemographic profile of study participants showed that the age ranges from 16 to 42 years old, making mean and standard deviation of 26.2 years and 5.4 years respectively. Majority 83 (55.3\%) were between in 21-30 years age group while $22(14.7 \%)$ are below 20 years. Majority of the subjects 107 (71.3\%) were from urban area. Majority 125 (83.3\%) of the subjects were Hindus. Most of the study subjects 131 (87.3\%) were married. Of all the study subjects, 50 (33.3\%) were illiterate or educated only up to primary level and only $15(10.0 \%)$ were educated up to graduation and above. Majority 93(62.0\%) were unemployed. It was found that $53(35.3 \%)$ were from upper and middle socioeconomic status, while 97 (64.7\%) were from lower socioeconomic status. Most of the subjects 81 (64.0\%) were from nuclear family.

When the knowledge of contraception domain was assessed, it was found that overall knowledge was there in 106 (70.7\%) subjects while knowledge of emergency contraception was seen in $51(34.0 \%)$ subjects, out of which only 11 (7.3\%) had good knowledge. The study findings revealed mass media as most common source of information. Attitude wise assessment of emergency contraception showed that $112(74.7 \%)$ subjects had favorable attitude towards its use.

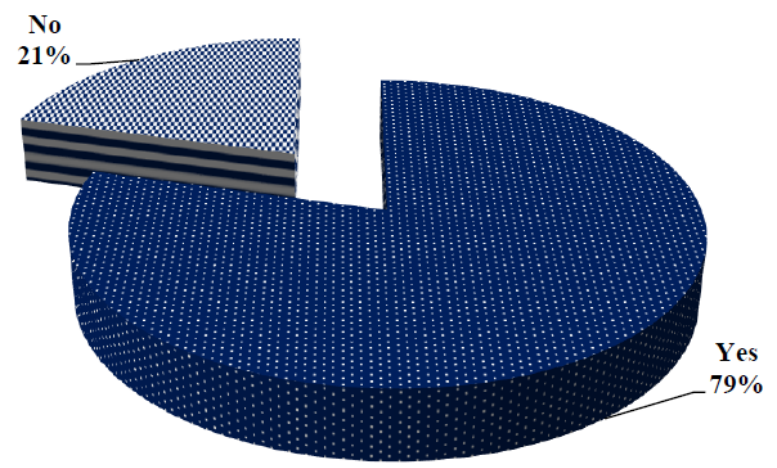

Figure I.Practice of emergency contraception

It was observed that out of 150 participants, only 31 (21\%) participants used emergency contraceptive pills (Figure 1).

Among the users of emergency contraceptives, the mean time of use of this contraceptive was 2.8 with standard deviation of 0.85 , the range being 1-10 times. $\ln 15$ (48.4\%) women, it was recommended by the doctor, while 12 (38.7\%) had used the ECPs by watching media.

In 13 (41.9\%) subjects (Figure 2), the reason for using emergency contraception was non usage of any contraceptive method, 7 (22.9\%) were used it due to missed pills of regular contraception while 4 (12.9\%) were using this emergency contraception as a regular method of contraception or were also using it repeatedly. Even after use of emergency contraception, 19 (61.3\%) had not started any regular method of contraception.

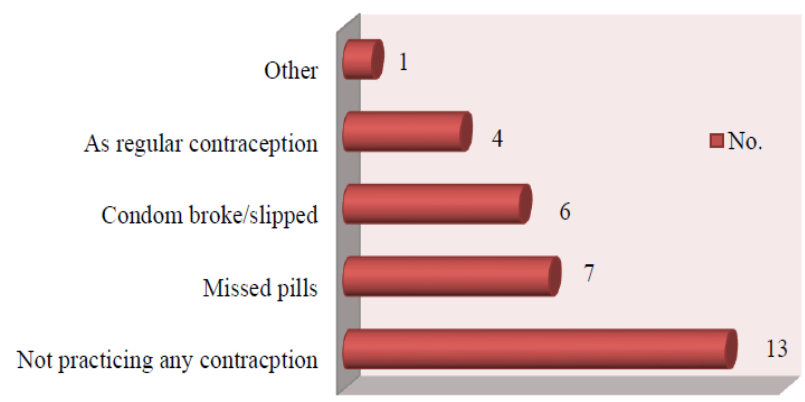

Figure 2.Reasons for using emergency contraception When the factors affecting the practice of emergency contraception were studied (Table 1), it was found factors like address, educational status, socioeconomic status, knowledge of contraception and emergency contraception, use of other methods of contraception were significantly affecting the practice of emergency contraception. The subjects who belong to urban area were 2.7 (1.00-7.29) times more odds of using the emergency contraceptive as compared to the participants from rural area. Higher the educational status and socioeconomic status, more was the use of emergency contraception. Users of regular 
contraception were significantly associated [2.7(1.007.29)] with more usage of emergency contraception as compared to non-users. In addition, knowledge of other methods of contraception and emergency contraception was significantly associated with the usage of emergency contraception. Attitude and other factors were not significantly associated with practice of emergency contraception.

Table I.Determinants of emergency contraceptive pill use

\begin{tabular}{|c|c|c|c|c|}
\hline $\begin{array}{l}\text { Determinants of emergency contraceptive } \\
\text { pill use }\end{array}$ & $\begin{array}{l}\text { Users } \\
(\mathrm{n}=31)\end{array}$ & $\begin{array}{c}\text { Non users } \\
(n=119)\end{array}$ & $\begin{array}{c}\text { OR } \\
(95 \% \mathrm{Cl}) \\
\end{array}$ & P-value \\
\hline \multicolumn{5}{|c|}{ Age (in years) } \\
\hline$<20$ & $3(13.6)$ & $19(86.4)$ & $0.48(0.12-1.96)$ & \multirow{3}{*}{0.590} \\
\hline $21-30$ & $17(20.5)$ & $66(79.5)$ & $0.79(0.33-1.88)$ & \\
\hline$\geq 31$ & $11(24.4)$ & $34(75.6)$ & 1 (Ref) & \\
\hline \multicolumn{5}{|c|}{ Address } \\
\hline Urban & $27(25.2)$ & $80(74.8)$ & 1 (Ref) & \multirow{2}{*}{0.02} \\
\hline Rural & $4(9.3)$ & $39(90.7)$ & $2.7(1.00-7.29)$ & \\
\hline \multicolumn{5}{|c|}{ Religion } \\
\hline Hindu & $24(19.2)$ & $101(80.8)$ & $0.61(0.22-1.62)$ & \multirow{2}{*}{0.321} \\
\hline Muslim and others & $7(28.0)$ & $18(72.0)$ & 1 (Ref) & \\
\hline \multicolumn{5}{|c|}{ Marital status } \\
\hline Married & $29(22.1)$ & $102(77.9)$ & 1 (Ref) & \multirow{2}{*}{0.243} \\
\hline Unmarried/ Divorced/ widow/ widower & $2(10.5)$ & $17(89.5)$ & $0.41(0.09-1.89)$ & \\
\hline \multicolumn{5}{|c|}{ Educational status } \\
\hline Illiterate and primary & $4(8.0)$ & $46(92.0)$ & $4.25(1.39-12.94)$ & \multirow{2}{*}{0.007} \\
\hline$\geq$ Secondary & $27(27.0)$ & $73(73.0)$ & 1 (Ref) & \\
\hline \multicolumn{5}{|c|}{ Occupation } \\
\hline Working & $10(17.5)$ & $47(82.5)$ & $0.72(0.31-1.68)$ & \multirow{2}{*}{0.460} \\
\hline Nonworking & $21(22.6)$ & $72(77.4)$ & 1 (Ref) & \\
\hline \multicolumn{5}{|c|}{ Socioeconomic status } \\
\hline Upper class (Upper, Upper middle, Middle) & $20(37.7)$ & $33(62.3)$ & 1 (Ref) & \multirow{2}{*}{$<0.0001$} \\
\hline Lower class (Lower middle, Lower) & $11(11.3)$ & $86(88.7)$ & $3.32(1.72-6.40)$ & \\
\hline \multicolumn{5}{|c|}{ Type of family } \\
\hline Nuclear & $17(21.0)$ & $64(79.0)$ & 1 (Ref) & \multirow{2}{*}{0.916} \\
\hline Joint/ three generation & $14(20.3)$ & $55(79.7)$ & $0.95(0.43-2.12)$ & \\
\hline \multicolumn{5}{|c|}{ Age at marriage } \\
\hline$<20$ years & $7(17.5)$ & $33(82.5)$ & $0.79(0.29-1.98)$ & \multirow{2}{*}{0.313} \\
\hline$\geq 21$ years & $23(19.1)$ & $87(80.9)$ & 1 (Ref) & \\
\hline \multicolumn{5}{|c|}{ Knowledge of contraception } \\
\hline Yes & $27(25.5)$ & $79(74.5)$ & 1 (Ref) & \multirow{2}{*}{0.02} \\
\hline No & $4(9.1)$ & $40(90.0)$ & $3.41(1.11-10.44)$ & \\
\hline \multicolumn{5}{|c|}{ Use of other methods of contraception } \\
\hline Yes & $21(35.6)$ & $38(64.4)$ & 1 (Ref) & \multirow{2}{*}{$<0.0001$} \\
\hline No & $10(11.0)$ & $81(89.0)$ & $4.47(1.92-10.43)$ & \\
\hline
\end{tabular}




\begin{tabular}{|c|c|c|c|c|}
\hline \multicolumn{5}{|c|}{ Knowledge of Emergency Contraception } \\
\hline Yes & $29(56.8)$ & $22(43.2)$ & 1 (Ref) & \multirow{2}{*}{$<0.0001$} \\
\hline No & $2(2.0)$ & $97(98.0)$ & $63.93(14.18-30.21)$ & \\
\hline \multicolumn{5}{|c|}{ Attitude towards use of emergency contraception } \\
\hline Favorable & $26(23.2)$ & $86(76.8)$ & 1 (Ref) & \multirow{2}{*}{0.186} \\
\hline Not-favorable & $5(13.2)$ & $33(86.8)$ & $1.99(0.70-5.63)$ & \\
\hline
\end{tabular}

*Multiple Responses.

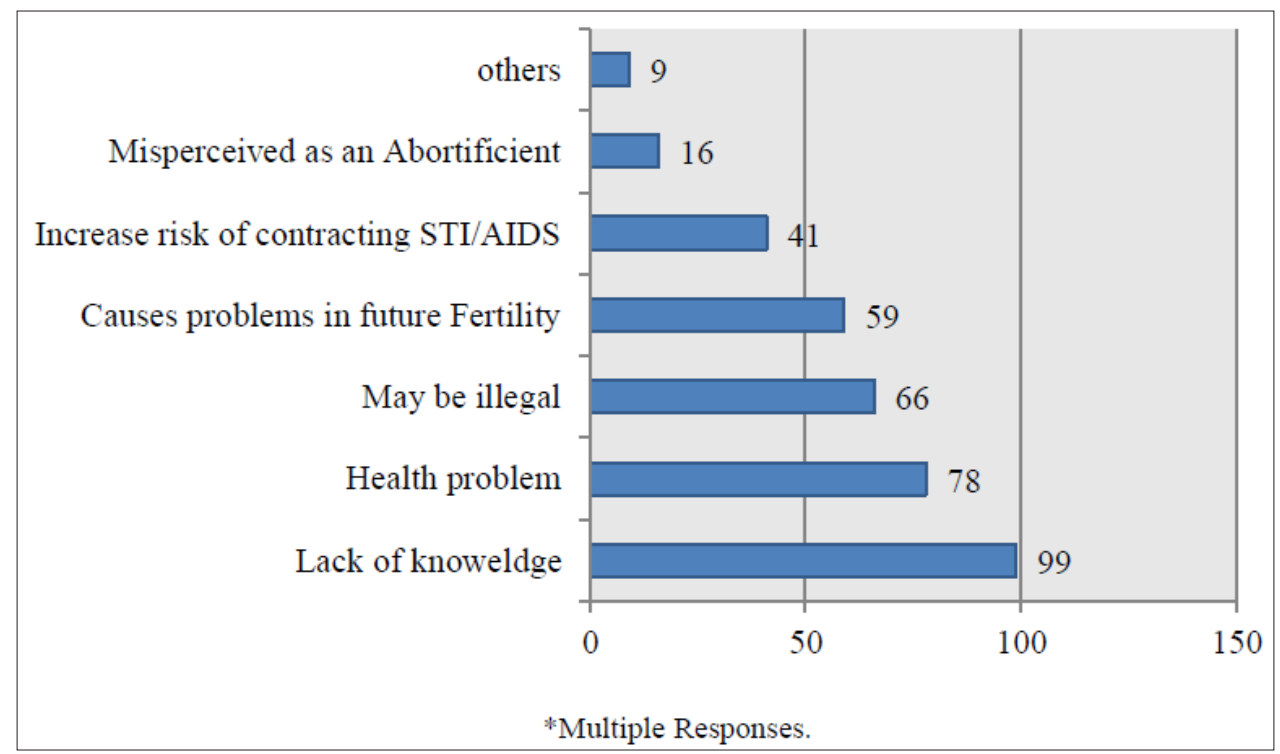

Figure I.Determinants of emergency contraceptive pill use

Barriers in usage of emergency contraception were presented in Figure 3. The most common and important barrier was lack of knowledge 99 (66.0\%) followed by the mistaken belief that it has long term effects on health 78 (52.0\%). Around 59 (39.3\%) subjects thought that this will affect their future fertility. The study subjects misperceived emergency contraception as illegal 66 (44.0\%) and also as abortifacient 16 (10.7\%).

\section{Discussion}

India's family planning program offers a wide range of modern contraceptive options. ECPs were officially introduced under the Family Welfare Programme in 2002-03. $\mathrm{EC}$ has a definite place in preventing unwanted pregnancies in present day society as an emergency measure in cases of rape, incest, failure of barrier or natural contraceptive methods, and unprotected or unplanned intercourse. ${ }^{12}$ ECPs are now a part of the Essential Drug List (EDL) for primary healthcare and have been included in Accredited Social Health Activist's (ASHA), Auxiliary Nurse Midwife's (ANM) and Lady Health Visitor's (LHV) kits to address unwanted pregnancies. In 2005, ECPs became available as an Over the Counter (OTC) drug, when pharmacies were allowed to sell the product without prescription. ${ }^{13}$ Despite easy availability, the level of awareness of this method of contraception remains limited. Many women still don't use regular contraception and may need emergency contraception for unprotected coitus.

The current study reflects overall 106 (70.7\%) subjects had knowledge of contraception, although 51 (34.0\%) have heard of Emergency contraception, detailed and specific knowledge is poor and misleading information is high. This might be due to illiteracy and lack of awareness. This study finding was comparable to the findings of Tesfaye T et al. ${ }^{14}$ In the present study, the attitude towards emergency contraception revealed that 112 (74.7\%) had favorable attitude. We have come across positive attitude of 53\%$100 \%$ during literature review. ${ }^{4,10,13}$ The finding of this study also falls in this range. However, this doesn't mean that we should not work on this issue. There are still many misconceptions and wrong beliefs which discourage the ECP use. Hence, all this needs to be addressed to increase its utilization. Out of 150 study subjects only 31 (21\%) participants had have ever used emergency contraceptive pills. This result is higher than the result obtained from other study. ${ }^{10}$ The reason could be due to more no. of educated women participants in this study who ever used ECP as compared to the study by Abate $\mathrm{M}$ et al. ${ }^{10}$ Factors like women belonging to urban area, education, 
socioeconomic status and knowledge of contraception and emergency contraception and ever used contraceptive were the significant determinants of practice of Emergency contraception. In a study by Mehra $\mathrm{R}^{13}$ in Chandigarh, it was found that $70 \%$ respondents were from urban area which was similar to our study findings. The participants from urban might have more awareness and more access to the availability of EC as compared to the rural area. Women belonging to urban area had higher knowledge as these women were more exposed to different medias like TV, Newspapers etc. as a source of knowledge as compared to women from rural area. In a study ${ }^{14}$ among women seeking abortion care, only 9 (10.1\%) women had awareness about EC while in another study by Awasthi $\mathrm{S}^{2}$ and others, awareness of emergency contraception was $19.95 \%$. The increased awareness in the current study could be attributed to a greater number of literate females as compared to above mentioned studies. Women's education seems to influence EC use; women higher education has been linked to higher EC use. Similarly, more accessibility may be seen in subjects from higher socioeconomic status. They have better awareness about EC than those with low family income. This may be due to the fact that good income widens the social interaction which in turn helps them to acquire more information regarding modern methods of family planning. Similar results observed by other author. ${ }^{10,14}$ The study findings revealed mass media as most common source of information which was consistent with other study findings. ${ }^{2,14}$ Different subjects offered different reasons for EC non-use including lack of knowledge, fear of effect on future fertility and health, misconceptions like its use being illegal and many more. Promoting these products through mass media particularly giving more emphasis on frequency of use and time limit would be more advantageous and should be strengthened so that it will reach many clients at a time.

\section{Limitation of the Study}

The study suffers from the usual limitation of a cross sectional study. It is focused on women who were seeking abortion, a specific population with failure in preventing pregnancy; it may not reflect the general condition of women in the city. In addition, the study populations from private health facilities were not included in the study so that this study might not be representing the entire population. The study also did not discover any information from the service providing side of emergency contraceptive in the health facilities.

\section{Conclusion}

The study revealed that there is a low trend of use of modern contraceptives. As a whole it can be concluded that Knowledge, and practice of emergency contraceptive is low whereas all had positive attitude towards emergency contraceptive use. The major reason for low usage was lack of adequate knowledge on the method, misperceptions of the adverse effects of this method, fear of effect on future fertility. Regular and repeated use of emergency contraception instead of using regular contraceptive methods was also observed in some study subjects. Factors like women belonging to urban area, education, socioeconomic status and knowledge of contraception and emergency contraception and ever used contraceptive were the significant determinants of practice of Emergency contraception. Much more effort should be done on information education and communication of awareness and practice of modern contraceptives. Thus, it is important to improve the knowledge of emergency contraception with the help of media, medical or paramedical workers and NGOs working in the field of health.

\section{Acknowledgement}

We would like to acknowledge the Indian Council of Medical Research (ICMR) for their grant support for this project in the form of Short-Term Studentship (STS).

\section{Conflict of Interest: None}

\section{References}

1. Dhumale DM, Lokare PO, Jawarkar AK et al. Sociodemographic determinants of Medical termination of pregnancy and its association with contraceptive practices. International Journal of Basic and Applied Medical Science 2014; 4(2): 126-31. Available From: https://www.ijrcog.org/index.php/ijrcog/article/ view/5209. [Google Scholar/ ResearchGate].

2. Awasthi S, Rawat CMS, Jha S et al. Evaluation of emergency contraceptive use among reproductive women in Nainital District of Uttarakhand, India. Indian Journal of Maternal and Child Health 2013; 15(2): 1-6. [Google Scholar, ResearchGate].

3. Tapare VS, Parande MA, Borle PS. Unmet need for contraception among married women of reproductive age in rural Maharashtra. Int J Community Med Public Health 2017; 4: 3365-71. Available From: https://www. ijcmph.com/index.php/ijcmph/article/view/1775. [Google Scholar, ResearchGate]

4. Tapare VS, Parande MA, Borle PS. Contraceptive needs and practices among married women of reproductive age in rural Maharashtra. Int J Med Sci Public Health 2017; 6(6): 1-6. [Google Scholar, ResearchGate].

5. Singh S, Maddow-Zimet I. Facility-based treatment for medical complications resulting from unsafe pregnancy termination in the developing world, 2012: a review of evidence from 26 countries. BJOG, 2015. Available From: https://obgyn.onlinelibrary.wiley.com/doi/ full/10.1111/1471-0528.13552. [PubMed, Google Scholar, ResearchGate]. 
6. Jamieson M, Hertweck S, Sanfilippo J. Emergency contraception: Lack of awareness among patients presenting for pregnancy termination. Journal of Pediatric and Adolescent Gynecology 1999; 12(1): 11-5. Available From: https://www.sciencedirect.com/ science/article/pii/S1083318896701729. [PubMed, Google Scholar, ResearchGate].

7. Lakde RN, Parande MA, Wakankar PS. Knowledge of emergency contraception among women seeking abortion services at tertiary care hospital in Western Maharashtra. Int J Med Sci Public Health 2018; 7: 507-513. Available From: https://www.hindawi. com/journals/bmri/2019/7209274/ [Google Scholar, ResearchGate].

8. Gupta RK, Verma A, Shora T. KAP on Emergency Contraception among currently married females aged 20-49 years in rural area of Jammu district, J\&K. Indian Journal of Maternal and Child Health 2012; 14(1): 1-6. [Google Scholar, ResearchGate].

9. Khiste S, Dank G, Rachkonda L et al. Knowledge, attitude and practice (KAP survey) of emergency contraception among women seeking termination of pregnancy at a tertiary care hospital in Maharashtra. International Journal of Recent Trends in Science and Technology 2015; 17(1): 10-13. Available From: https:// statperson.com/Journal/ScienceAndTechnology/ Article/Volume17Issue1/17_1_3.pdf. [Google Scholar, ResearchGate]

10. Abate M, Assefa N, Alemayehu T. Knowledge, attitude, practice, and determinants emergency contraceptive use among women seeking abortion services in Dire Dawa, Ethiopia. PLoS ONE 2014; 9(10): e110008. Available From: https://journals.plos.org/plosone/ article?id=10.1371/journal. pone.0110008. [PubMed, Google Scholar].

11. Kokane AM, Khadilkar HA. Knowledge of emergency contraception in women attending MTP centre at rural tertiary care hospital in India. Asian Journal of Pharmaceutical and Health Sciences 2012; 2(2): 333-335. Available From: http://ajphs. com/article/2012/2/2/333-335. [Google Scholar, ResearchGate].

12. Hatcher RA. Emergency contraception: The Nation's Best Kept Secret. Bridging the Gap Communications, Decatur, GA. 1995. Available From: https://www. amazon.com/Emergency-Contraception-NationsBest-Secret/dp/096388753X. [Google Scholar, ResearchGate].

13. Reeti M, Poonam G, Deepti D et al. Knowledge of emergency contraception among women coming for induced abortion. The Journal of Obstetrics and Gynecology of India 2006; 56(3): 233-235. Available From: http://medind.nic.in/jaq/t06/i3/jaqt06i3p233. pdf. [Google Scholar, ResearchGate].

14. Tesfaye T, Tilahun T, Girma E. Knowledge, attitude and practice of emergency contraceptive among women who seek abortion care at Jimma university specialized hospital, southwest Ethiopia. BMC Women's Health 2012; 12: 3. Available From: https://bmcwomenshealth. biomedcentral.com/articles/10.1186/1472-6874-12-3. [PubMed, Google Scholar, ResearchGate]. 